\title{
Long-term Oncologic Outcomes Following Robotic Liver Resections for Primary Hepatobiliary Malignancies: A Multicenter Study
}

\author{
Sidrah Khan, $\mathrm{MD}^{\S}$, Rachel E. Beard, MD*, T. Peter Kingham, $\mathbf{M D}^{\dagger}$, Yuman Fong, $\mathbf{M D}^{\phi}$, \\ Thomas Boerner, MD $^{\dagger}$, John B. Martinie, MD ${ }^{\ddagger}$, Dioneses Vrochides, MD $\ddagger$, Joseph F. Buell, \\ $\mathrm{MD}^{\dagger \dagger}$, Eren Berber, MDף, Bora Kahramangil, MDף, Roberto I. Troisi, MD ${ }^{\mathcal{N}}$, Aude Vanlander, \\ $\mathrm{MD}^{\S}$, Michele Molinari, MD§, and Allan Tsung, MD§ \\ §Department of Surgery, University of Pittsburgh Medical Center, Pittsburgh, PA \\ *Department of Surgery, Rhode Island Hospital, Providence, RI \\ †Department of Surgery, Memorial Sloan-Kettering Cancer Center, New York, NY \\ ${ }^{\circledR}$ Department of Surgery, City of Hope National Medical Center, Duarte, CA \\ ¥Department of Surgery, Carolinas Medical Center, Charlotte, NC \\ t†Department of Surgery, Tulane University, New Orleans, LA \\ IDepartment of General Surgery, Cleveland Clinic, Cleveland, $\mathrm{OH}$ \\ ${ }^{5}$ Department of General, Hepatobiliary and Liver Transplantation Surgery, Ghent University \\ Hospital Medical School, Ghent, Belgium
}

\begin{abstract}
Objective: Robotic liver surgery (RLS) has emerged as a feasible alternative to laparoscopic or open resections with comparable perioperative outcomes. Little is known about the oncologic adequacy of RLS. The aim of this study was to investigate the long-term oncologic outcomes for patients undergoing RLS for primary hepatobiliary malignancies.
\end{abstract}

Methods: We performed an international, multi-center, retrospective study of patients who underwent RLS for hepatocellular carcinoma (HCC), cholangiocarcinoma (CC), or gallbladder cancer (GBC) between 2006-2016. Age, gender, histology, resection margin status, extent of surgical resection, disease-free survival (DFS) and overall survival (OS) were retrospectively collected and analyzed.

Results: Of the 61 included patients, 34 (56\%) had RLS performed for HCC, 16 (26\%) for CC, and $11(18 \%)$ for GBC. The majority of resections were non-anatomical or segmental resections (39.3\%), followed by central hepatectomy (18\%), left lateral sectionectomy (14.8\%), left hepatectomy $(13.1 \%)$, right hepatectomy (13.1\%), and right posterior segmentectomy (1.6\%). R0

Corresponding Author and Requests for Reprints: Allan Tsung, MD, Division of Hepatobiliary and Pancreatic Surgery, University of Pittsburgh Medical Center, 3471 Fifth Ave, Suite 300, Pittsburgh, PA 15213, Tel: 412-692-2001, Fax: 412-692-2002, tsunga@upmc.edu.

Conflict of Interest Statement: The authors have no conflicts of interest to report. 
resection was achieved in $94 \%$ of $\mathrm{HCC}, 68 \%$ of CC, and $81.8 \%$ of GBC patients. Median hospital stay was 5 days and conversion to open surgery was needed in 7 patients (11.5\%). Grade III-IV Dindo-Clavien complications occurred in 7 patients with no perioperative mortality. Median follow-up was 75 months (95\% CI 36-113) and 5-year OS and DFS were 56\% and 38\%, respectively. When stratified by tumor type, 3-year OS was $90 \%$ for HCC, $65 \%$ for GBC and $49 \%$ for $\mathrm{CC}(\mathrm{p}=0.01)$.

Conclusion: RLS can be performed for primary hepatobiliary malignancies with long-term oncologic outcomes comparable to published open and laparoscopic data.

\section{Introduction}

Primary hepatobiliary cancers (PHBC) are one of the most common cancers, with hepatocellular carcinoma (HCC) ranking second in cancer related deaths worldwide and sixth in cancer related deaths in developed countries $(1,2)$. More than 20,000 new diagnoses of HCC are made yearly in the United States with an annual incidence of approximately 780,000 new cases worldwide (2-4). Cholangiocarcinoma (CC) and gallbladder cancer (GBC) less common than HCC, share a similar poor prognosis $(1,5)$.

The surgical management of PHBC has evolved over recent decades with the advent of minimally invasive surgery. Since the introduction of laparoscopic liver surgery (LLS) in the 1990s, multiple studies have reported on its safety and feasibility (6-13). In 2008, the first international consensus meeting was held in Louisville, Kentucky, to establish indications for LLS. These criteria included utilization of laparoscopy for solitary lesions smaller than 5 $\mathrm{cm}$, for lesions in segments 2 through 6 , for left lateral sectionectomies, and reserving right or left hepatectomies for surgeons highly experienced in laparoscopy (14). Since 2008, laparoscopy gained significant popularity for liver resections and a second international consensus conference was held in Morioka, Japan in 2014 with the goal of developing more specific guidelines (15). They concluded that minor LLS is now standard practice, whereas major LLS is considered innovative, and robotic liver resections should be categorized as developmental. An increased interest in the utilization of robot techniques for hepatic resections emerged as the limitations associated with LLS including its restricted visualization to two dimensions and limited range of motion to four degrees became more apparent (17-19).

The short-term outcomes following RLS have recently been studied, with many reports demonstrating similar perioperative morbidity and mortality when compared to LLS (6,19-24,31). Despite limited reports on the long-term oncologic outcomes following LLS demonstrating no differences in overall or disease-free survival when compared to open liver resections (OLR), little is known in regards to the actual oncologic efficacy of RLS (16, 25-30). This study aims to examine the oncologic outcomes of RLS performed for PHBC with particular interest in overall survival (OS) and recurrence rates (RR). 


\section{Methods}

\section{Patients and Indications}

Patients with a diagnosis of $\mathrm{HCC}, \mathrm{CC}$, or GBC were discussed at multidisciplinary conferences at their respective institutions. Diagnoses were based on clinical presentation, elevated serum tumor markers (alpha feto-protein for HCC and CA19.9 for CC and GBC), and cross-sectional imaging. Surgical resectability was based on patient's ability to undergo general anesthesia and pneumoperitoneum while following general consensus guidelines for LLS as surrogate $(14,32)$. RLS was performed with the intention to cure and diagnoses were confirmed by institutional surgical pathology.

\section{Operative technique}

All patients underwent surgery with the assistance of the da Vinci Surgical System (Intuitive Surgical, Inc., Sunnyvale, CA) robotic-assisted platform. Details on the setup, use, and technical considerations of the robotic system were similar to that found in published literature (22, 32-34). Intraoperative ultrasound was performed to guide resection. Ligasure, harmonic scalpel, and endovascular GIA staplers were used during parenchymal transections and control of vasculature. If safe or successful resection was not attainable, the operation was converted to open.

\section{Data Collection}

Six institutions across the United States and Europe collected data on patients who underwent RLS for HCC, CC, or GBC between 2006 and 2016. The study was carried out by all of all participating institutions with approval from the Institutional Review Board (IRB: PRO17020317). Data collection included demographic and clinical variables such as age, gender, prior abdominal surgeries, American Society of Anesthesiologists (ASA) class, body mass index (BMI), and presence of cirrhosis. Perioperative and operative data collection included time of diagnosis, site of primary tumor, conversion to open surgery, resection type, occurrence of concomitant procedures, operative time, estimated blood loss (EBL), length of stay (LOS), complications, readmissions, and reoperations. Oncologic data collection included type of cancer, size of tumor, lymph node status, vascular or peri-neural invasion, resection margin status, recurrence of disease, time to recurrence, treatment of recurrence, and survival. OS was defined as the time from diagnosis to last documented follow-up visit or death for any cause. Disease free survival (DFS) was defined as the interval between the date of surgery to the date of first clinical or radiological diagnosis of recurrent disease.

\section{Statistical Analysis}

The database was analyzed using SPSS v24 software. Continuous variables were expressed as means and medians and were compared using Student t-test if normally distributed or Wilcoxon-Mann-Whitney test for non-parametric variables. Discrete variables were expressed as frequency and percentages and Chi-square or Fisher exact test, when appropriate, were used for comparisons. Kaplan-Meier curves were used to calculate the probability of survival and comparisons were performed using Log-rank test. Patients who 
were alive, and patients who did not have recurrent disease at the time of the last follow-up were censored. Two-tail tests were used for all comparison and $\mathrm{p}$ values equal or less than 0.05 were considered statistically significant. Complications were classified based on the Dindo-Clavien grading system (35).

\section{Results}

\section{Demographics and Peri-operative Outcomes}

Between September 2006 and November 2016, 61 patients underwent RLS for PHBC. Thirty-four (56\%) of the 61 patients were diagnosed with HCC, 16 (26\%) with CC, and 11 (18\%) with GBC. The median age was 66 years (range 32-91 years) with females comprising $41 \%$ of the overall cohort. Cirrhosis was present in $22.8 \%(n=14)$ of patients, of which 12 had Childs-Pugh class A cirrhosis, two had class B and none had class C cirrhosis. Four (6.5\%) patients underwent prior liver resections including two right hepatectomies for HCC, one emergent partial right lobectomy for a ruptured HCC, and one unspecified liver resection (Table 1).

There were no perioperative mortalities. Approximately one-third of patients $(34.4 \%, \mathrm{n}=23)$ experienced perioperative complications, with $11.5 \%(\mathrm{n}=7)$ classified as Dindo-Clavien Grade 3 or greater (30). Complications of respiratory function were the most common $(n=11)$, including atelectasis/ pulmonary edema $(n=3)$, respiratory insufficiency $(n=2)$, respiratory failure $(n=2)$, pneumonia $(n=2)$, and $\mathrm{PE}(\mathrm{n}=2)$. One patient with HCC and alcoholic cirrhosis developed liver failure, ultimately requiring liver transplantation. The median LOS was five days (range 2-91) (Table 2).

\section{Operative Outcomes}

The majority of patients underwent a non-anatomical liver resection or segmentectomy $(\mathrm{n}=24,39.3 \%)$, followed by left lateral sectionectomy $(\mathrm{n}=9,14.8 \%)$ left hepatectomy $(\mathrm{n}=8$, $13.1 \%)$, right hepatectomy ( $\mathrm{n}=8,13.1 \%)$, and one patient underwent right posterior segmentectomy. Eighteen percent $(n=11)$ of patients underwent central liver resection, all of which were for GBC.

Median operative time was 240 minutes (range 99-790 min) and EBL was $100 \mathrm{cc}$ (range 2-2200 cc) (Table 2). Seven cases (11.5\%) required conversion to open. Of the patients who were converted to open, three underwent a non-anatomical liver resections, three underwent a right hepatectomy, and one underwent a left hepatectomy. Reasons for conversion included uncontrolled bleeding $(\mathrm{n}=1)$, advanced disease $(\mathrm{n}=2)$, inadequate margins $(\mathrm{n}=2)$, adhesions $(\mathrm{n}=1)$, and technical difficulty $(\mathrm{n}=1)$. Of the seven patients who underwent conversion to open, three had multifocal HCC with tumor sizes ranging from $5.0-14.5 \mathrm{~cm}$ and four had CC of which three were Klatskin tumors. All patients who underwent conversion to open had an EBL higher than the median (range 500-1200cc) and LOS longer than our median (range 8 -91 days). Patients with $\mathrm{CC}$ had higher likelihood of conversion to open $(\mathrm{n}=4,25 \%)$ in comparison to patients with $\mathrm{HCC}(\mathrm{n}=3,8.8 \%)$ and $\mathrm{GBC}(\mathrm{n}=0,0 \%) .75 \%(\mathrm{n}=3)$ of these were Klatskin tumors. One was Bismuth stage 1 and two were Bismuth stage 2 (36). All three required a lobectomy, bile duct resection, as well as a Roux-en-Y hepaticojejunostomy. 


\section{Pathologic Characteristics}

The majority of patients $(49.2 \%, \mathrm{n}=30)$ were found to have moderately-differentiated tumors. Median tumor size was $3.4 \mathrm{~cm}$ (range $0.3-16 \mathrm{~cm}$ ). R0 resection was achieved in $85.2 \%$, with a sub-analysis showing R0 resection in $94.1 \%$ in patients with HCC, $81.8 \%$ in GBC, and $68.8 \%$ in CC (Table 3). Patients with HCC most commonly had tumor burden within one segment $(\mathrm{n}=13,38.2 \%)$, while the majority of patients with $\mathrm{CC}$ and GBC had tumor burden within two segments $(n=6,37.5 \% ; n=11,100 \%$, respectively). The average number of lymph nodes resected for HCC was 2 (range 0-6), GBC 5 (range 0-9), and CC 2.5 $(0-13)$.

\section{Oncologic Outcomes}

Median follow up for patients was 75 months (95\% CI 26-113 mos), with a RR of $37.7 \%$ $(\mathrm{n}=23)$. For patients who were diagnosed with $\mathrm{HCC}, 44 \%(\mathrm{n}=15)$ developed recurrence of which the majority $(\mathrm{n}=10)$ recurred in the liver. Patients with $\mathrm{CC}$ had an RR of $31.2 \%(\mathrm{n}=5)$ with the most common site also being the liver $(n=3)$. Recurrence was lowest in patients with GBC, $27.2 \%(n=3)$ with all three patient having evidence of malignancy in multiple organs. There were no port site recurrences found. For the entire cohort, systemic chemotherapy $(n=9)$ and liver directed therapy $(n=6)$ were the most common methods of management of the recurrence disease. At five years the overall survival (OS) and diseasefree survival (DFS) for the entire cohort were 56\% and 38\% respectively (Figure 1). Subgroup analysis showed a 3 -year survival of $90 \%$ for HCC, $65 \%$ for GBC, and $49 \%$ for CC (Figure 2).

\section{Discussion}

The results of this multicenter study suggest that RLS performed for PHBC demonstrate similar long-term oncologic adequacy as compared to laparoscopic or open techniques. A review of over 2800 patients who underwent LLS for HCC found a 5-year OS rate between $50-75 \%$ and a DFS rate ranging from 31-38.2\% (7). Our cohort had similar outcomes with an OS of 56\% and DFS of 38\%. Lai et al. studied 41 patients who underwent RLS for HCC reporting an R0 rate of $93 \%$ and OS rate of $94 \%$, comparable to the R0 rate of $94 \%$ and 3 year OS of $90 \%$ observed with HCC in the current study (37). Takahara et al. reported a 5year OS/DFS rate of 70.9\%/39.3\% in patients undergoing OLR (25). Subgroup analyses of patients with HCC in our study showed comparable OS and DFS. One study by Wu et. al. reviews a larger cohort of patients $(n=38)$ with HCC and discusses their ability to increase the number of patients undergoing MIS with the addition of RLS. However, this study does not examine any long-term oncologic outcomes (38).

The only current data on RLS for CC consists of one study comparing 10 robotic radical resections to 32 OLR for hilar cholangiocarcinoma. This study concluded an inferior DFS and OS rate associated with RLS (33). It is difficult to compare these patients to our cohort as only three of the 16 patients within our cohort underwent RLS for hilar type CC. Our data showed a median survival time of 17 months, $100 \%$ conversion rate, higher EBL and longer LOS. The data from our study, along with the limited historical data on RLS for CC, suggest inferiority in outcomes for patients undergoing RLS for extra-hepatic CC. Uy et al. 
evaluated 37 patients with intrahepatic cholangiocarcinoma (IHC). They reported 5-year OS and DFS rates for the laparoscopic cohort of $77.9 \%$ and $56.2 \%$, respectively (31). Though these rates seem higher than the 5 year OS/DFS rate of $56 \% / 38 \%$ and the 3 -year CC specific OS rate of $49 \%$ that we observed, their cohort comprised of intrahepatic CC only and their median follow-up was limited to 17.

In regards to patients with GBC, the only study reporting on RLS compared five patients who underwent a robotic radical cholecystectomy to 18 patients who underwent OLR. Their maximum follow-up was 17 months and only one patient underwent a lymphadenectomy (39). Recently, an expert consensus statement on laparoscopic resection of GBC showed that this approach did not worsen the prognosis and allowed comparable retrieval of lymph nodes to open surgery in experienced centers (40). Palanisamy et al. studied 14 patients with GBC undergoing LLS and reported an R0 resection rate of $100 \%$ and 5 year OS of 68.8\% (41). Though the $\mathrm{R} 0$ resection rate observed in our study for $\mathrm{GBC}(\mathrm{R} 0=81.8 \%)$ is lower, we show comparable long-term survival outcomes with a 3 -year OS rate of $65 \%$.

Despite this study reporting comparable oncologic outcomes to LLS, the median operative time associated with RLS (240 min) as seen in prior published studies, is longer $(21,33,42$, 43). When stratified by type of liver resection, our data shows the longest operative times to be associated with right lobectomies and shortest operative times with left lateral sectionectomies. $790 \mathrm{~min}$, the longest operative time was seen at an institution that performed less then five RLS cases over the 10-year period, emphasizing variation in outcome depending on experience of institution. The heterogeneity of pathology also plays a factor, as resections for hilar cholangiocarcinoma were also associated with the longer operative times, similar to published studies (31). Despite this, we believe that minimally invasive approach can still offer benefits including shorter LOS, decreased EBL and postoperative complications when compared to $\operatorname{OLR}(11,44)$.

The major limitation to this study is that though it is one of the largest series to date of RLS for PHBC, 61 patients over a ten-year period emphasizes how infrequently RLS is performed for PHBC. Our data does shows a trend of increase in utilization of the robot with time as the number of RLS performed from 2006-2011 ranged from 1-4 per year, which then increased to 4-13 per year starting in 2012. It also shows that some institutions started performing RLS but never continued, exhibiting that support and access of this technology is not the same throughout all institutions performing liver surgery. We included robotic cases from a 10-year period because it allows us to not only track patients oncologic outcomes over an extended period, but also gives us a real world experience of the perioperative outcomes from both low and high volume centers.

This retrospective study by nature of its design, allows for selection bias, as each individual surgeon was able to decide on the candidacy for robotic surgery. The lower number of cirrhotic patients with HCC (32\%) in this study in comparison to published literature (56-100\%) was likely due to the fact that surgeons chose to perform RLS in overall healthier patients without cirrhosis, who would likely better tolerate longer anesthesia time (45). Cipriani et al performed a matched comparison between cirrhotic patients and non-cirrhotic patients reporting that the former exhibited a higher incidence of recurrence, supporting that 
the lower RR reported in this study could also be due to the smaller percentage of patients with cirrhosis (46).

The current study has several strengths including the relatively large number of participants who were operated in USA and Europe in a variety of institutions that ranged from very low volume centers to higher volume centers allowing us to study the wide variety of the outcomes.

In conclusion, this international, multicenter study examines the long-term oncologic outcomes of patients undergoing RLS for PHBC and demonstrates them to be non-inferior to the published data on laparoscopic or open liver resections for PHBC. As RLS has become an increasingly utilized alternative to laparoscopic or open surgery, future efforts in prospective observational or randomized controlled trials must be designed to assess the overall benefits and possible limitations of robotic assisted surgery for liver resections for hepatobiliary malignancies.

\section{Acknowledgements}

The authors would like to acknowledge Doreen Esposito, Lillian Martin and Donielle Neal for their assistance with data collection and the IRB approval process.

Financial Support Statement: This research did not receive any specific support in either funding or equipment.

\section{References:}

1. Benson AB, D'Angelica MI, Abrams TA, et al. NCCN clinical practice guidelines in oncology: hepatobiliary cancers Journal of the National Comprehensive Cancer Network : JNCCN 2009; 7(4), 350-91. [PubMed: 19406039]

2. Kabbach G, Assi HA, Bolotin G, Schuster M, Lee HJ, \& Tadros M, Hepatobiliary Tumors: Update on Diagnosis and Management. Journal of Clinical and Translational Hepatology 2015: 3, 169-181. [PubMed: 26623263]

3. El-Serag HB, \& Kanwal F, Obesity and hepatocellular carcinoma: Hype and reality. Hepatology 2014; 60(3), 779-781. [PubMed: 24753107]

4. Torre LA, Bray F, Siegel RL, Ferlay J, Lortet-tieulent J, \& Jemal A Global Cancer Statistics, 2012. CA: A Cancer Journal of Clinicians., 2015; 65(2), 87-108.

5. Sheth S, Bedford A, \& Chopra S Primary gallbladder cancer: Recognition of risk factors and the role of prophylactic cholecystectomy. American Journal of Gastroenterology 2000; 95(6), 1402 1410. [PubMed: 10894571]

6. Cherqui D, Husson E, Hammoud R et al. Laparoscopic liver resections: a feasibility study in 30 patients. Annals of Surgery 2000; 232(6), 753-62. [PubMed: 11088070]

7. Nguyen KT, Gamblin TC, \& Geller DA World Review of Laparoscopic Liver Resection-2,804 Patients. Annals of Surgery 2009; 250(5), 831-841. [PubMed: 19801936]

8. Cai XJ, Yang J, Yu H, Liang X, Wang YF, Zhu ZY, \& Peng SY Clinical study of laparoscopic versus open hepatectomy for malignant liver tumors. Surgical Endoscopy and Other Interventional Techniques 2008; 22(11), 2350-2356. [PubMed: 18297354]

9. Simillis C, Constantinides VA, Tekkis PP, Darzi A, Lovegrove R, Jiao L, \& Antoniou A Laparoscopic versus open hepatic resections for benign and malignant neoplasms-a meta-analysis. Surgery 2007; 141(2), 15-20

10. Xiong J, Altaf K, Javed MA, et al. Meta-analysis of laparoscopic vs open liver resection for hepatocellular carcinoma. World Journal of Gastroenterology 2012; 18(45), 6657. [PubMed: 23236242] 
11. Nguyen KT, Laurent A, Dagher I, Geller DA, Steel J, Thomas MT, Gamblin TC Minimally Invasive Liver Resection for Metastatic Colorectal Cancer. Annals of Surgery 2009; 250(5), 842848. [PubMed: 19806058]

12. Bagante F, Spolverato G, Strasberg SM, et al. Minimally Invasive vs. Open Hepatectomy: a Comparative Analysis of the National Surgical Quality Improvement Program Database. Journal of Gastrointestinal Surgery 2016; 20(9), 1608-1617. [PubMed: 27412321]

13. Ratti F, Cipriani F, Ariotti R, Gagliano A, Paganelli M, Catena M, \& Aldrighetti L Safety and feasibility of laparoscopic liver resection with associated lymphadenectomy for intrahepatic cholangiocarcinoma: a propensity score-based case-matched analysis from a single institution. Surgical Endoscopy and Other Interventional Techniques 2016; 30(5), 1999-2010. [PubMed: 26194257]

14. Buell JF, Cherqui D, Geller DA, O’Rourke N, Iannitti D, Dagher I, World Consensus Conference on Laparoscopic Surgery. The international position on laparoscopic liver surgery: The Louisville Statement, 2008. Annals of Surgery 2009; 250(5), 825-30. [PubMed: 19916210]

15. Wakabayahi G, Cherqu D, Geller DA, et al. Recommendations for Laparoscopic Liver Resection. A Report From the Second International Consensus Conference Held in Morioka. Annals of Surgery 2015; 261(4), 619- 629. [PubMed: 25742461]

16. Xiao L, Xiang L, Li J, Chen J, Fan Y, \& Zheng S Laparoscopic versus open liver resection for hepatocellular carcinoma in posterosuperior segments. Surgical Endoscopy 2015; 29(10), 2994 3001. [PubMed: 25899815]

17. Berguer R, Rab GT, Abu-Ghaida H, Alarcon A, \& Chung J A comparison of surgeons' posture during laparoscopic and open surgical procedures. Surgical Endoscopy 1997; 11(2), 139-42. [PubMed: 9069145]

18. Cadiere GB, Himpens J, Germay O, Izizaw R, Degueldre M, Vandromme J, Bruyns J Feasibility of robotic laparoscopic surgery: 146 cases. World Journal of Surgery 2001, 25(11), 1467-77. [PubMed: 11760751]

19. Ocuin LM, \& Tsung A Robotic liver resection for malignancy: Current status, oncologic outcomes, comparison to laparoscopy, and future applications. Journal of Surgical Oncology 2015; 112(3), 295-301. [PubMed: 26119652]

20. Han DH, Choi SH, Park EJ, Kang DR, Choi GH, \& Choi JS Surgical outcomes after laparoscopic or robotic liver resection in hepatocellular carcinoma: a propensity-score matched analysis with conventional open liver resection. The International Journal of Medical Robotics and Computer Assisted Surgery 2016; 12(4), 735-742. [PubMed: 26537176]

21. Tsung A, Geller DA, Sukato DC, Sabbaghian S, Tohme S, Steel J, Bartlett DL Robotic Versus Laparoscopic Hepatectomy. Annals of Surgery 2014; 259(3), 549-555. [PubMed: 24045442]

22. Berber E, Akyildiz HY, Aucejo F, Gunasekaran G, Chalikonda S, \& Fung J Robotic versus laparoscopic resection of liver tumours. HPB 2010; 12(8), 583-586. [PubMed: 20887327]

23. Kingham TP, Leung U, Kuk D, et al. Robotic Liver Resection: A Case-Matched Comparison. World Journal of Surgery 2016; 40(6), 1422-1428. [PubMed: 26913732]

24. Giulianotti PC, Coratti A, Sbrana F, et al. Robotic liver surgery: Results for 70 resections. Surgery 2011; 149(1), 29-39. [PubMed: 20570305]

25. Takahara T, Wakabayashi G, Beppu T, et al. Long-term and perioperative outcomes of laparoscopic versus open liver resection for hepatocellular carcinoma with propensity score matching: a multiinstitutional Japanese study. Journal of Hepato-Biliary-Pancreatic Sciences 2015; 22(10), 721-727. [PubMed: 26096910]

26. Lee W, Park J-H, Kim J-Y, et al. Comparison of perioperative and oncologic outcomes between open and laparoscopic liver resection for intrahepatic cholangiocarcinoma. Surgical Endoscopy 2016; 30(11), 4835-4840. [PubMed: 26902611]

27. Ahn S, Cho A, Kim EK, \& Paik KY Favorable Long-Term Oncologic Outcomes of Hepatocellular Carcinoma Following Laparoscopic Liver Resection. Journal of Laparoendoscopic \& Advanced Surgical Techniques 2016; 26(6), 447-452. [PubMed: 27152858]

28. Jiang X, Liu L, Zhang Q, et al. Laparoscopic versus open hepatectomy for hepatocellular carcinoma: long-term outcomes. Journal of B.U.ON. : Official Journal of the Balkan Union of Oncology 2016; 21(1), 135-41. [PubMed: 27061541] 
29. Leong WQ, Ganpathi IS, Kow AWC, Madhavan K, \& Chang SKY Comparative study and systematic review of laparoscopic liver resection for hepatocellular carcinoma. World Journal of Hepatology 2015; 7(27), 2765-2773. [PubMed: 26644820]

30. Levi Sandri GB, Spoletini G, Masciana G, et al. The role of minimally invasive surgery in the treatment of cholangiocarcinoma. European Journal of Surgical Oncology (EJSO) 2017, 43.

31. Uy BJ, Han HS, Yoon YS, \& Cho JY Laparoscopic liver resection for intrahepatic cholangiocarcinoma. J Laparoendosc Adv Surg Tech A 2015; 25(4), 272-277. [PubMed: 25789408]

32. Giulianotti PC, Corrati A, Angelini M, Robotics in General Surgery. Archives of Surgery 2003; 138(7), 777. [PubMed: 12860761]

33. Xu Y, Wang H, Ji W, et al. Robotic radical resection for hilar cholangiocarcinoma: perioperative and long-term outcomes of an initial series. Surgical Endoscopy and Other Interventional Techniques 2016; 30(7), 3060- 3070. [PubMed: 27194255]

34. Chan OC, Tang CN, Lai EC, Yang GP, \& Li MK Robotic hepatobiliary and pancreatic surgery: a cohort study. Journal of Hepato-Biliary Pancreatic Sciences 2011; 18(4), 471-480. [PubMed: 21487754]

35. Dindo D, Demartines N, \& Clavien P-A Classification of Surgical Complications. Annals of Surgery 2004; 240(2), 205-213. [PubMed: 15273542]

36. Bismuth H, Nakache R, Diamond T. Management strategies in resection for hilar cholangiocarcinoma. Ann Surg. 1992;215:31-8 [PubMed: 1309988]

37. Lai ECH, Yang GPC, \& Tang CN Robot-assisted laparoscopic liver resection for hepatocellular carcinoma: short-term outcome. The American Journal of Surgery 2013; 205(6), 697-702. [PubMed: 23561638]

38. Wu Y, Hu R, Lai H, \& Lee P Robotic-assisted minimally invasive liver resection. Asian Journal of Surgery. 2014 37(2), 53-57. [PubMed: 24642128]

39. Shen BY, Zhan Q, Deng XX, Bo H, Liu Q, Peng CH, \& Li HW Radical resection of gallbladder cancer: Could it be robotic? Surgical Endoscopy and Other Interventional Techniques 2012; 26(11), 3245-3250. [PubMed: 22648103]

40. Han HS, Yoon YS, Agrawal AK, et al. Laparoscopic Surgery for Gallbladder Cancer: An Expert Consensus Statement. Digestive Surgery 2018; DOI: 10.1159/000486207

41. Palanisamy S, Patel N, Sabnis S, Palanisamy N, et al. Laparoscopic radical cholecystectomy for suspected early gall bladder carcinoma: thinking beyond convention. Surgical Endoscopy and Other Interventional Techniques 2016; 30(6), 2442-2448. [PubMed: 26416372]

42. Xiu CJ, Yang J, Hong Y, Xiao L, Yi FW, Zi YZ, Shu YP, Clinical study of laparoscopic versus open hepatectomy for malignant liver tumors. Surgical Endoscopy 2008: 22:2350-23. [PubMed: 18297354]

43. Zhang Y, Chen X, \& Sun D Short-term Outcomes of Laparoscopic Versus Open Right Hemihepatectomy for Hepatocellular Carcinoma. Surgical Laparoscopy, Endoscopy \& Percutaneous Techniques. 2016: 26(6).

44. Lee KF, Chong CN, Wong J et al. Long-Term Results of Laparoscopic Hepatectomy Versus Open Hepatectomy for Hepatocellular Carcinoma: A Case-Matched Analysis. World J Surg 2011: 35: 2268. [PubMed: 21842300]

45. Xiong J, Altaf K, Javed M, et al. Meta-analysis of laparoscopic vs open liver resection for hepatocellular carcinoma. World Journal of Gastroenterology. 2012, 75(45), 6657.

46. Cipriani F, Fantini C, Ratti F, et al. Lapaproscopic liver resections for hepatocellular carcinoma. Can we extend the surgical indication in cirrhotic patients? Surgical Endoscopy 2018 32(2):617626 [PubMed: 28717870] 


\section{Synopsis:}

An international, multicenter study investigating the long-term oncologic outcomes of robotic liver resections for primary hepatobiliary cancers. Median follow-up was 75 months with 5-year OS and DFS was 56\% and 38\%, respectively. 


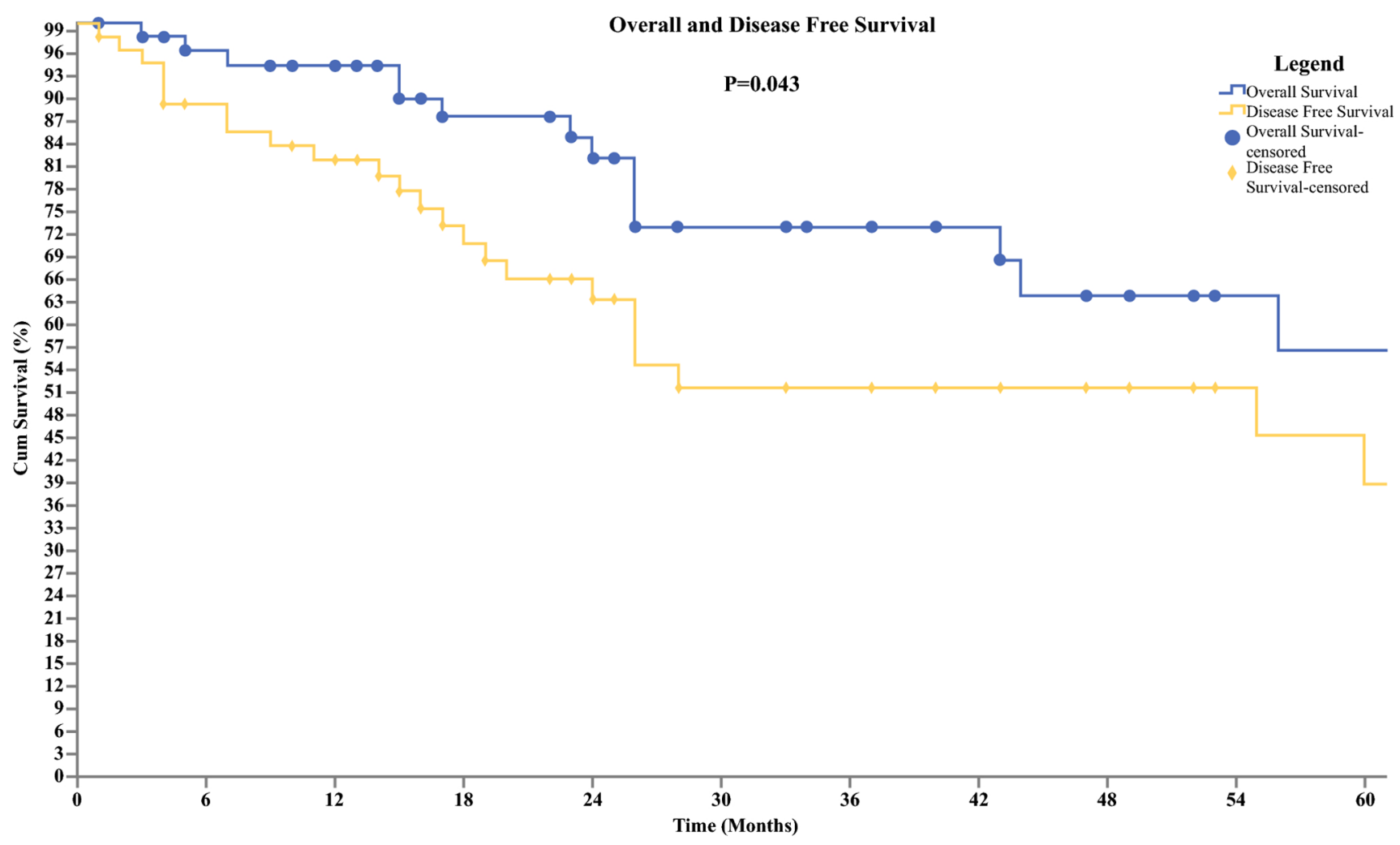

Figure 1.

Overall and Disease Free Survival of Primary Hepatobiliary Malignancies. Overall survival was available for 61 patients. (Mean [SD], 78 [10.3] months; median, 75 months). Diseasefree survival was available for 61 patients, 23 patients had recurrent disease. (Mean [SD], 57.6 [9.4] months; median, 55 months) 


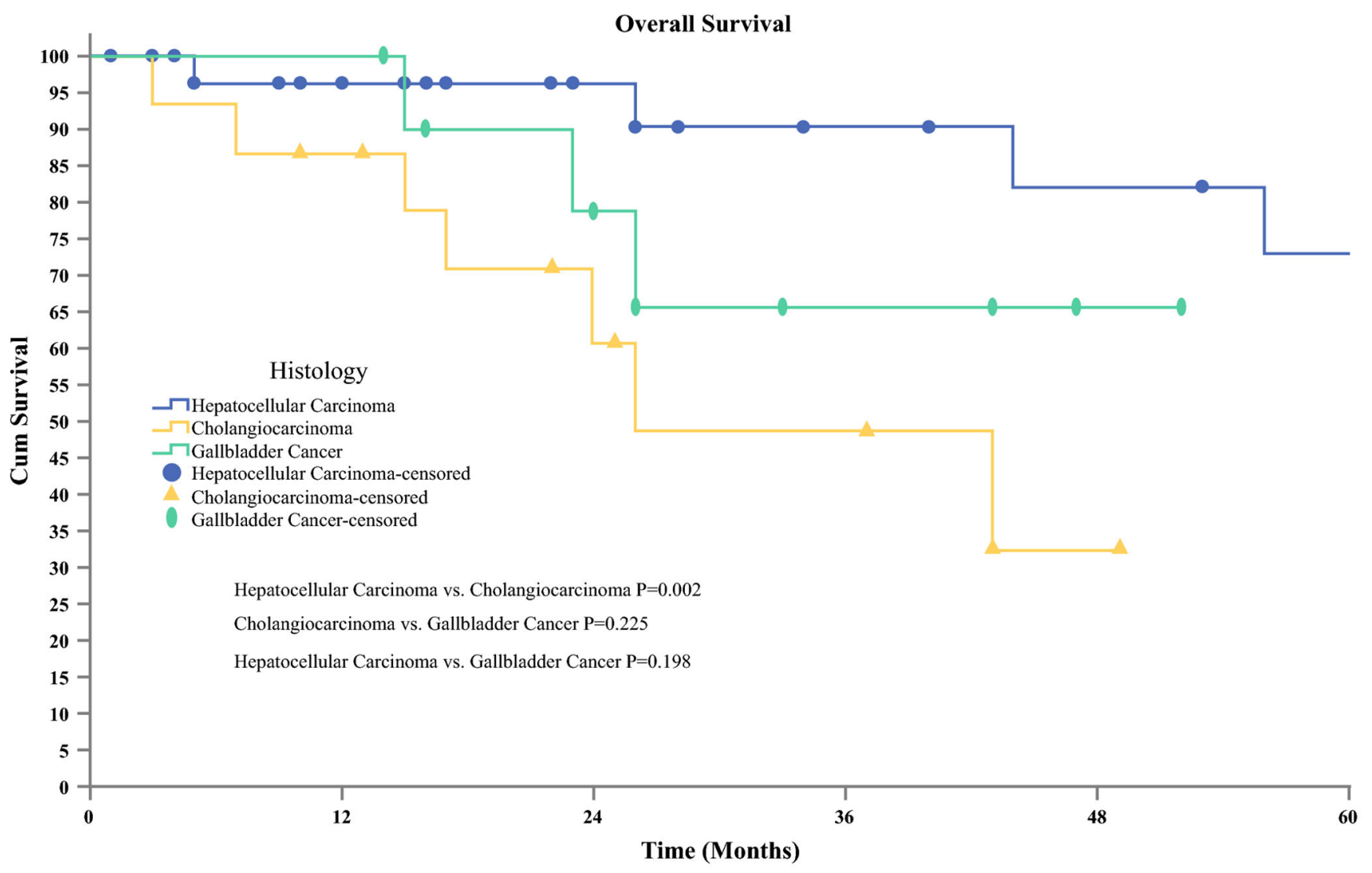

Figure 2.

Overall Patient Survival Stratified by Type of Malignancy. Overall survival was available for 61 patients. Hepatocellular Carcinoma ( $\mathrm{n}=34)$ (Mean [SD], 94.2 [12.3] months). Cholangiocarcinoma ( $\mathrm{n}=16$ ) (Mean [SD], 31.6 [4.7] months), Gallbladder Cancer $(\mathrm{n}=11)$ (Mean [SD], 41.6 [4.9] months). 
Table 1.

Baseline Demographic and Clinical Characteristics of the Study Population $(n=61)$

\begin{tabular}{|c|c|c|c|c|}
\hline Characteristics & Entire Cohort $(n=61)$ & $\begin{array}{l}\text { Hepatocellular } \\
\text { Carcinoma }(n= \\
\text { 34) }\end{array}$ & Cholangiocarcinoma $(n=16)$ & Gallbladder Cancer $(n=11)$ \\
\hline Age, years, median, (Range) & $66(32-91)$ & $66(32-91)$ & $67(50-81)$ & $63(57-85)$ \\
\hline Females, n, (\%) & $25(41.0)$ & $8(23.5)$ & $11(68.8)$ & $6(54.5)$ \\
\hline $\begin{array}{l}\text { Body Mass Index (BMI), } \\
\text { median, (Range) }\end{array}$ & $28(20-44)$ & $28(20-44)$ & $27.1(20-38)$ & $25(20-44)$ \\
\hline $\begin{array}{l}\text { Prior Abdominal Surgery, n, } \\
(\%)\end{array}$ & $33(54.1)$ & $16(47.1)$ & $9(56.3)$ & $8(72.7)$ \\
\hline Cholecystectomy & $13(21.3)$ & $4(11.7)$ & $2(12.5)$ & $7(63.6)$ \\
\hline Obstetric and gynecology & $6(9.8)$ & $3(8.8)$ & $2(12.5)$ & $1(9.0)$ \\
\hline Liver resection & $4(6.5)$ & $4(11.7)$ & $0(0.0)$ & $0(0.0)$ \\
\hline Others * & $7(11.4)$ & $4(11.7)$ & $3(18.7)$ & $0(0.0)$ \\
\hline \multicolumn{5}{|l|}{ ASA Classification } \\
\hline 2 & $12(19.7)$ & $7(20.6)$ & $4(25.0)$ & $1(9.1)$ \\
\hline 3 & $41(67.2)$ & $25(73.5)$ & $8(50.0)$ & $8(72.7)$ \\
\hline 4 & $8(13.1)$ & $2(5.9)$ & $4(25.0)$ & $2(18.2)$ \\
\hline Presence of cirrhosis, $n,(\%)$ & $14(22.9)$ & $11(31.4)$ & $3(16.7)$ & $0(0.0)$ \\
\hline
\end{tabular}

Legend: ASA = American Society of Anesthesiologists.

* Other prior abdominal surgeries include: Appendectomy, hernia repair, small bowel resection, exploratory laparotomy, urachal cyst excision. 
Table 2.

Surgical Interventions and Postoperative Outcomes

\begin{tabular}{|c|c|c|c|c|}
\hline & Entire Cohort $(n=61)$ & Hepatocellular Carcinoma(n=34) & Cholangiocarcinoma $(n=16)$ & Gallbladder Cancer $(n=11)$ \\
\hline \multicolumn{5}{|l|}{ Hepatic Resection, n, (\%) } \\
\hline Non-anatomic resection & $24(39.3)$ & $16(47.1)$ & $8(50.0)$ & $0(0.0)$ \\
\hline Left lateral segmentectomy & $9(14.8)$ & $6(17.6)$ & $3(18.8)$ & $0(0.0)$ \\
\hline Left lobectomy & $8(13.1)$ & $5(14.7)$ & $3(18.8)$ & $0(0.0)$ \\
\hline Right lobectomy & $8(13.1)$ & $6(17.6)$ & $2(12.5)$ & $0(0.0)$ \\
\hline Right posterior segmentectomy & $1(1.6)$ & $1(2.9)$ & $0(0.0)$ & $0(0.0)$ \\
\hline Central liver resection & $11(18.0)$ & $0(0.0)$ & $0(0.0)$ & $11(100)$ \\
\hline $\begin{array}{l}\text { Operative time, minute, } \\
\text { median, (range) }\end{array}$ & $240(99-790)$ & $246(114-790)$ & $265(99-652)$ & $219(99-790)$ \\
\hline $\begin{array}{l}\text { Concomitant procedure during } \\
\text { the index operation, } n,(\%)\end{array}$ & $29(47.5)$ & $13(38.2)$ & $8(50)$ & $8(72.7)$ \\
\hline Radiofrequency ablation & $6(9.8)$ & $3(8.8)$ & $2(12.5)$ & $1(9.1)$ \\
\hline Cholecystectomy & $16(26.2)$ & $10(29.4)$ & $6(37.5)$ & n.a. \\
\hline Lymphadenectomy & $16(26.2)$ & $4(11.7)$ & $5(31.2)$ & $7(63.6)$ \\
\hline Lysis of adhesions & $4(6.5)$ & $1(2.9)$ & $0(0.0)$ & $3(27.2)$ \\
\hline Bile Duct Excision & $3(18.8)$ & $0(0.0)$ & $3(18.8)$ & $0(0.0)$ \\
\hline Other * & $4(6.5)$ & $0(0.0)$ & $2(12.5)$ & $2(18.2)$ \\
\hline $\begin{array}{l}\text { Conversion to open surgery, } n, \\
(\%)\end{array}$ & $7(11.5)$ & $3(8.8)$ & $4(25.0)$ & $0(0.0)$ \\
\hline $\begin{array}{l}\text { Estimated blood loss in } \mathrm{ml} \text {, } \\
\text { median, (range) }\end{array}$ & $100(2-2200)$ & $125(10-2200)$ & $250(10-1200)$ & $50(10-200)$ \\
\hline $\begin{array}{l}\text { Admission to the intensive care } \\
\text { unit, } n,(\%)\end{array}$ & $25(41)$ & $19(55.8)$ & $4(25)$ & $2(18.2)$ \\
\hline $\begin{array}{l}\text { Hospital stay, days, median, } \\
\text { (range) }\end{array}$ & $5(2-91)$ & $4(2-91)$ & $5(2-36)$ & $4(2-9)$ \\
\hline $\begin{array}{l}\text { Patients requiring blood } \\
\text { transfusion, } n,(\%)\end{array}$ & $2(3.3)$ & $2(5.9)$ & $0(0.0)$ & $0(0.0)$ \\
\hline Perioperative morbidity, $n,(\%)$ & $23(37.7)$ & $12(35.2)$ & $7(43.8)$ & $4(36.4)$ \\
\hline Clavien-Dindo Grade 1 & $7(11.5)$ & $4(11.7)$ & $2(12.5)$ & $1(9.1)$ \\
\hline Clavien-Dindo Grade 2 & $9(14.8)$ & $3(8.8)$ & $2(12.5)$ & $2(18.2)$ \\
\hline $\begin{array}{l}\text { Clavien-Dindo Grade 3A or } \\
\text { 3B }\end{array}$ & $4(6.5)$ & $2(5.9)$ & $2(12.5)$ & $1(9.1)$ \\
\hline $\begin{array}{l}\text { Clavien-Dindo Grade 4A or } \\
\text { 4B }\end{array}$ & $3(4.9)$ & $3(8.8)$ & $1(6.3)$ & $0(0.0)$ \\
\hline \multicolumn{5}{|l|}{ Type of Complication } \\
\hline Intra-abdominal & $5(8.2)$ & $3(8.8)$ & $2(12.5)$ & $0(0.0)$ \\
\hline Pulmonary & $11(18.0)$ & $4(11.7)$ & $3(18.8)$ & $3(27.2)$ \\
\hline Cardiovascular & $1(1.6)$ & $1(2.9)$ & $0(0.0)$ & $0(0.0)$ \\
\hline Infectious & $1(1.6)$ & $0(0.0)$ & $1(6.3)$ & $0(0.0)$ \\
\hline Liver failure & $1(1.6)$ & $1(2.9)$ & $0(0.0)$ & $0(0.0)$ \\
\hline
\end{tabular}

Ann Surg Oncol. Author manuscript; available in PMC 2019 September 01. 


\begin{tabular}{|c|r|r|r|r|}
\hline & Entire Cohort $(\mathbf{n}=\mathbf{6 1})$ & Hepatocellular Carcinoma(n=34) & Cholangiocarcinoma $(\mathbf{n = 1 6})$ & Gallbladder Cancer $(\mathbf{n = 1 1})$ \\
\hline Other $^{* *}$ & $4(6.5)$ & $3(8.8)$ & $1(6.3)$ & $1(9.1)$ \\
\hline Perioperative mortality, $\mathbf{n}, \mathbf{( \% )}$ & $0(0.0)$ & $0(0.0)$ & $0(0.0)$ & $0(0.0)$ \\
\hline
\end{tabular}

Legend: Non-anatomic resection= wedge or segmentectomy

*ther concomitant procedures include: Intraoperative ultrasound, hepatic arterial infusion catheter, resection of peritoneal mass, partial omentectomy. Intra-abdominal complications include: Ileus, biloma, re-opening of laparotomy, hepatic abscess. Pulmonary complications include: atelectasis, pneumonia, pulmonary embolus, respiratory insufficiency, pulmonary edema. Cardiovascular complications include: arrhythmias. Infectious complications include: Clostridium defficile, urinary tract infection

**

Other perioperative complications include: acute thalamic infarct, decubitus ulcer, rectus sheath hematoma, reopening of recent laparotomy 
Table 3.

Tumor Characteristics, Pathologic Staging, and Long-term Outcomes

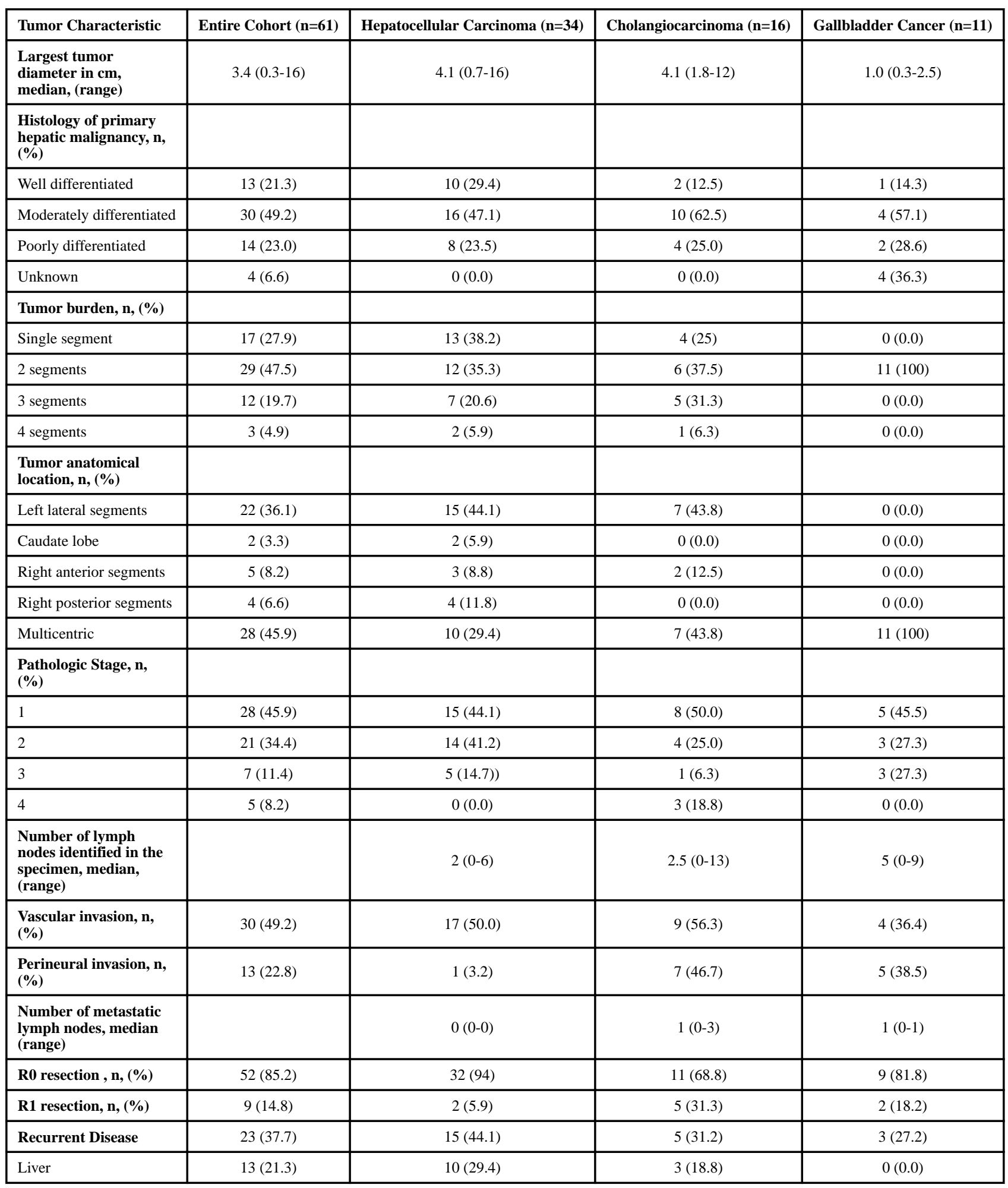




\begin{tabular}{|c|c|c|c|c|}
\hline Tumor Characteristic & Entire Cohort $(\mathbf{n}=61)$ & Hepatocellular Carcinoma $(n=34)$ & Cholangiocarcinoma (n=16) & Gallbladder Cancer $(\mathrm{n}=11)$ \\
\hline Multiple Organs & $7(11.4)$ & $2(5.9)$ & $2(12.5)$ & $3(27.3)$ \\
\hline Other ${ }^{*}$ & $3(4.9)$ & $3(8.8)$ & $0(0.0)$ & $0(0.0)$ \\
\hline \multicolumn{5}{|l|}{$\begin{array}{l}\text { Management of } \\
\text { Recurrent Disease }\end{array}$} \\
\hline Liver resection & $3(4.9)$ & $1(2.9)$ & $1(6.3)$ & $1(9.1)$ \\
\hline Systemic chemotherapy & $9(14.8)$ & $5(14.7)$ & $2(12.5)$ & $2(18.2)$ \\
\hline $\begin{array}{l}\text { Ablation or radiation } \\
\text { therapy }\end{array}$ & $2(3.3)$ & $2(5.9)$ & $0(0.0)$ & $0(0.0)$ \\
\hline $\begin{array}{l}\text { Liver Directed Therapy } \\
\text { (TACE / Yttrium 90) }\end{array}$ & $6(9.8)$ & $6(17.6)$ & $0(0.0)$ & $0(0.0)$ \\
\hline No therapy & $3(4.9)$ & $1(2.9)$ & $2(12.5)$ & $0(0.0)$ \\
\hline Other ${ }^{*}$ & $1(1.6)$ & $1(2.9)$ & $0(0.0)$ & $0(0.0)$ \\
\hline Adjuvant Therapy & $12(19.7)$ & $5(14.7)$ & $4(25)$ & $3(27.3)$ \\
\hline Systemic chemotherapy & $8(13.7)$ & $2(5.9)$ & $4(25)$ & $2(18.2)$ \\
\hline Radiotherapy & $1(1.6)$ & $0(0.0)$ & $0(0.0)$ & $1(9.1)$ \\
\hline $\begin{array}{l}\text { Liver Directed Therapy } \\
\text { (TACE / Yttrium 90) }\end{array}$ & $1(1.6)$ & $1(2.9)$ & $0(0.0)$ & $0(0.0)$ \\
\hline Liver transplantation & $1(1.6)$ & $1(2.9)$ & $0(0.0)$ & $0(0.0)$ \\
\hline
\end{tabular}

Legend: *Other areas of recurrent disease includes: resection bed, mesenteric nodules.

*ther management of recurrent disease includes: Ethanol embolization, sorafenib. 